\title{
Lateral Hypothalamic Area Glutamatergic Neurons and Their Projections to the Lateral Habenula Regulate Feeding and Reward
}

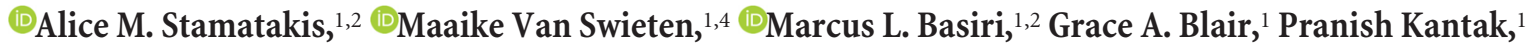 \\ and Garret D. Stuber ${ }^{1,2,3}$ \\ Departments of ${ }^{1}$ Psychiatry and Cell Biology and Physiology, ${ }^{2}$ Curriculum in Neurobiology, and ${ }^{3}$ Neuroscience Center, University of North Carolina at \\ Chapel Hill, Chapel Hill, North Carolina 27599, and ${ }^{4}$ Master program Neuroscience and Cognition, Brain Center Rudolf Magnus, Department of \\ Transitional Neuroscience, University Medical Center Utrecht, Utrecht 3584 CX, The Netherlands
}

The overconsumption of calorically dense, highly palatable foods is thought to be a major contributor to the worldwide obesity epidemic; however, the precise neural circuits that directly regulate hedonic feeding remain elusive. Here, we show that lateral hypothalamic area (LHA) glutamatergic neurons, and their projections to the lateral habenula ( $\mathrm{LHb})$, negatively regulate the consumption of palatable food. Genetic ablation of LHA glutamatergic neurons increased daily caloric intake and produced weight gain in mice that had access to a high-fat diet, while not altering general locomotor activity. Anterior LHA glutamatergic neurons send a functional glutamatergic projection to the LHb, a brain region involved in processing aversive stimuli and negative reward prediction outcomes. Pathway-specific, optogenetic stimulation of glutamatergic LHA-LHb circuit resulted in detectable glutamate-mediated EPSCs as well as GABA-mediated IPSCs, although the net effect of neurotransmitter release was to increase the firing of most LHb neurons. In vivo optogenetic inhibition of LHA-LHb glutamatergic fibers produced a real-time place preference, whereas optogenetic stimulation of LHA-LHb glutamatergic fibers had the opposite effect. Furthermore, optogenetic inhibition of LHA-LHb glutamatergic fibers acutely increased the consumption of a palatable liquid caloric reward. Collectively, these results demonstrate that LHA glutamatergic neurons are well situated to bidirectionally regulate feeding and potentially other behavioral states via their functional circuit connectivity with the LHb and potentially other brain regions.

Key words: aversion; feeding; habenula; hypothalamus; optogenetics; reward

Significance Statement

In this study, we show that the genetic ablation of LHA glutamatergic neurons enhances caloric intake. Some of these LHA glutamatergic neurons project to the lateral habenula, a brain area important for generating behavioral avoidance. Optogenetic stimulation of this circuit has net excitatory effects on postsynaptic LHb neurons. This is the first study to characterize the functional connectivity and behavioral relevance of this circuit within the context of feeding and reward-related behavior.

\section{Introduction}

The orchestration of complex motivated states, such as the seeking out and consumption of food are essential for an organism's survival. Optimal feeding behavior likely requires the activity of

Received March 26, 2015; revised Nov. 3, 2015; accepted Nov. 12, 2015.

Author contributions: A.M.S., P.K., and G.D.S. designed research; A.M.S., M.V.S., M.L.B., G.A.B., and P.K. performed research; A.M.S., M.V.S., M.L.B., G.A.B., and G.D.S. analyzed data; A.M.S. and G.D.S. wrote the paper.

This work was supported by The Klarman Family Foundation, The Brain and Behavior Research Foundation, the Foundation for Prader-Willi Research, the Foundation of Hope, the National Institute on Drug Abuse (DA032750 and DA038168), and the National Institute on Alcohol Abuse and Alcoholism (P60 AA011605); A.M.S. was supported by NS007431 and DA034472. We thank members of the Stuber laboratory for helpful discussion, the UNC vector core for viral packaging, Bradford Lowell for the Vglut2-IRES-Cre mice, Karl Deisseroth and Nirao Shah for viral constructs, and the UNC Neuroscience Center Microscopy Core (P30 NS045892). distinct neurocircuits that function not only to maintain energy homeostasis (Saper et al., 2002; Aponte et al., 2011; Krashes et al., 2011), but also to positively reinforce behaviors directed toward the approach and consumption of palatable foods. The lateral hypothalamic area (LHA) is a cellularly heterogeneous brain region (Berthoud and Münzberg, 2011) known to be critical for

The authors declare no competing financial interests.

Correspondence should be addressed to Dr. Garret D. Stuber, Departments of Psychiatry and Cell Biology and Physiology, Neuroscience Center, University of North Carolina at Chapel Hill, Chapel Hill, NC 27599. E-mail: gstuber@med.unc.edu.

DOI:10.1523/JNEUROSCI.1202-15.2016

Copyright $\odot 2016$ the authors $\quad 0270-6474 / 16 / 360302-10 \$ 15.00 / 0$ 
both feeding and reinforcement processes (Hoebel and Teitelbaum, 1962; Margules and Olds, 1962; Jennings et al., 2013, 2015). Our previous work demonstrated that optogenetic or chemogenetic stimulation of vesicular GABA transporter (VGat)-expressing LHA neurons (putative GABAergic neurons) produced both feeding and reward-related phenotypes (Jennings et al., 2015). In contrast, optogenetic stimulation of Vglut2expressing LHA neurons (putative glutamatergic neurons) suppressed feeding and produced aversive behavioral phenotypes. (Jennings et al., 2013). Thus, our previous results demonstrate that genetically distinct GABAergic and glutamatergic LHA subpopulations can produce opposing behavioral phenotypes. At the gross neuroanatomical level, the LHA sends widespread projections to many brain regions including the cortex, thalamus, midbrain, and hindbrain substructures (Berk and Finkelstein, 1982). These distinct neuronal projections likely arise from genetically, anatomically, and/or functionally diverse cell populations within the LHA. However, whether specific neuronal projections from molecularly identifiable LHA neurons are sufficient and/or necessary for feeding and other motivated behavioral states remains poorly understood. Here, we focus on the LHA projection to the lateral habenula $(\mathrm{LHb})$ to determine whether this particular circuit exerts control over aspects of feeding and reward-related behaviors. We sought to characterize the function of this projection because $\mathrm{LHb}$ neurons are known to encode aversive events and are involved in negatively regulating reward processing ( $\mathrm{Ma}-$ tsumoto and Hikosaka, 2007), likely because LHb neurons can indirectly inhibit ventral tegmental area (VTA) dopaminergic neurons (Christoph et al., 1986; Matsui and Williams, 2011; Lammel et al., 2012; Stamatakis and Stuber, 2012). A previous anatomical study demonstrated that glutamatergic projections from the LHA innervate LHb neurons that in turn project to the ventral midbrain (Poller et al., 2013). Thus, we hypothesized that VGlut2-expressing LHA neurons may be a critical negative regulator of feeding and reward, which may affect motivated behavior through direct excitation of LHb neurons.

\section{Materials and Methods}

\section{Subjects}

Adult (25-30 g) male VGlut2-ires-cre, Vgat-ires-cre (Vong et al., 2011), or wild-type litter mates and adult (25-30 g) C57BL/6J mice were used. Mice were maintained on a reverse $12 \mathrm{~h}$ light cycle (lights off at 07:00) with ad libitum access to food and water unless placed on a food restriction schedule for the free-licking experiment (see below). All fooddeprived mice were restricted to $90 \%$ of their initial body weight by administering one daily feeding of 2.5-3.0 g of standard grain-based chow (immediately following behavioral experiment, if performed). All procedures were conducted in accordance with the Guide for the Care and Use of Laboratory Animals, as adopted by the $\mathrm{NIH}$, and with approval of the Institutional Animal Care and Use Committee at the University of North Carolina (UNC) at Chapel Hill.

\section{Viral constructs}

Purified and concentrated adeno-associated viruses coding for Cre-inducible ChR2-eYFP [AAV5-EF1a-DIO-hChR2(H134R)-eYFP], NpHR3.0-eYFP (AAV5-EF1a-DIO-NpHR3.0-eYFP), eYFP (AAV5EF1a-DIO-eYFP), and taCasp3 (AAV2-FLEX-taCasp3-TEVp) were all packaged by the UNC Vector Core Facility at titers of $\sim 2 \times 10^{12}$ genome copies $/ \mathrm{ml}$.

\section{Stereotactic surgeries}

Mice were anesthetized with ketamine $(150 \mathrm{mg} / \mathrm{kg}$ body weight $)$ and xylazine $(50 \mathrm{mg} / \mathrm{kg}$ ) solution and placed in a stereotactic frame (Kopf Instruments). For the genetic ablation and optogenetic experiments, adult male VGlut2-ires-Cre-positive and -negative littermates (controls) were bilaterally microinjected with $0.3 \mu \mathrm{l}$ of virus into the anterior LHA using the following coordinates: $-1.0 \mathrm{~mm}$ posterior to bregma, \pm 0.9 $\mathrm{mm}$ lateral to midline, and $-6.0 \mathrm{~mm}$ ventral to skull surface. For the optogenetic experiments, mice were bilaterally implanted with $200-\mu \mathrm{m}$ diameter multimode optical fibers (0.37 NA) aimed directly above the $\mathrm{LHb}$ at $-1.7 \mathrm{~mm}$ posterior to bregma, -1.25 lateral to midline, and -3.24 ventral to the skull surface at a $15^{\circ}$ angle. For the retrobead mapping and quantification experiments, male C57BL/6J mice (The Jackson Laboratory) received quadruple injections (Nanoject) with $70 \mathrm{~nL}$ of red retrobeads (Lumafluor) in the LHb using the following coordinates: -1.4 and $-1.8 \mathrm{~mm}$ posterior to bregma, $\pm 0.43 \mathrm{~mm}$ lateral to the midline, and -3.3 ventral to the skull surface.

\section{Experimental timeline}

Genetic ablation of VGlut2 LHA neurons. Following surgery, VGlut2 ${ }^{\text {LHA }}:$ :taCasp3 and VGlut2 ${ }^{\mathrm{LHA}}:$ :Control mice were weighed daily. For 4 weeks, mice were given ad libitum access to standard grain-based chow (Harlan, 3.5 calories/g). Chow was weighed daily immediately following weighing of mice. After 4 weeks, before the introduction of the high-fat diet, VGlut ${ }^{\text {LHA }}:$ taCasp3 and VGlut $2^{\text {LHA }}$ ::Control mice were run through an open-field experiment (see Open-field behavior). After 4 weeks of access to grain-based chow, mice were given ad libitum access to both standard grain-based chow and a calorie-dense chow (Bioserv, High Fat diet; fat calories $=60 \%, 5.49$ calories $/ g$ ). Body weight, grain-based chow, and calorie-dense chow were weighed daily for at least $60 \mathrm{~d}$ postsurgery. Calories consumed were calculated by adding the calories from grain-based chow (3.5 calories/g) to the calories from high-fat chow (5.49 calories/g). Following the experiment, VGlut2 ${ }^{\mathrm{LHA}}::$ taCasp3 and $V G l u t 2^{\text {LHA }}:$ :Control were then rapidly decapitated, and in situ hybridization was performed (see Fluorescence in situ hybridization).

Retrobead experiment. Male C57BL/6J mice were injected with retrobeads (Lumafluor, stock concentration; see Stereotaxic surgery) and 4-6 weeks later confocal imaging was obtained to quantify LHbprojecting LHA neurons (see Histology, immunohistochemistry, and confocal microscopy).

Optogenetic behavioral experiments. Six to 8 weeks follow-

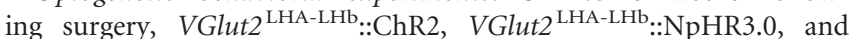
VGlut2 ${ }^{\text {LHA-LHb }:: C o n t r o l ~ m i c e ~ b i l a t e r a l l y ~ i m p l a n t e d ~ w i t h ~ o p t i c a l ~ f i b e r s ~}$ aimed above the LHb were run through a real-time place preference experiment (see Real-time place preference). Following the real-time place preference experiment (at least $24 \mathrm{~h}$ ), VGlut2 ${ }^{\mathrm{LHA}-\mathrm{LHb}}:: \mathrm{NpHR} 3.0$ and VGlut2 $2^{\text {LHA-LHb}:: C o n t r o l ~ m i c e ~ w e r e ~ r u n ~ t h r o u g h ~ t h e ~ l i q u i d ~ r e w a r d ~}$ consumption task (see Photoinhibition of VGlut2 ${ }^{\text {LHA-LHb }}:$ NpHR3.0 during reward consumption). Following the reward consumption task, mice were run through the quinine experiment (see Photoinhibition of VGlut $2^{\text {LHA-LHb }:: N p H R 3.0 ~ d u r i n g ~ r e w a r d ~ c o n s u m p t i o n) . ~}$

\section{Fluorescence in situ hybridization}

Mice were rapidly decapitated, and brains were snap frozen with dry ice in an embedding mold of OCT Compound (Fisher Scientific). Fresh, frozen brains were sectioned at $20 \mu \mathrm{m}$ on a cryostat (CM3050; Leica Biosystems) onto charged slides (Leica Biosystems). A given set of slides were then hybridized to either VGlut2 antisense and sense riboprobes. A 1749 bp riboprobe complementary to VGlut2-sense cDNA that was inserted into the pGEM- $4 \mathrm{Z}$ vector (Promega). Plasmid DNA was cut with either EcoRI or SalI to create a template for in vitro transcription. All probes were created using digoxigenin (DIG)-labeled nucleotides for detection. The SalI template was transcribed with Sp6 RNA Polymerase to generate the sense riboprobe, and the EcoRI template was transcribed with T7 RNA polymerase to generate the antisense riboprobe. Fluorescence in situ hybridization was performed at room temperature unless otherwise indicated. Tissue was dried at $50^{\circ} \mathrm{C}$, fixed in $4 \%$ DEPC-PFA for $15 \mathrm{~min}$, and washed in DEPC-PBS $3 \times 5 \mathrm{~min}$. The tissue was then acetylated in $1 \times$ triethanolamine- $\mathrm{HCl}$ with $0.25 \%$ acetic anhydride for $10 \mathrm{~min}$ and subsequently washed in DEPC-PBS $3 \times 5$ min each. Next, the tissue was prehybridized for $3 \mathrm{~h}$ at $65^{\circ} \mathrm{C}$ in hybridization buffer containing $5 \times$ saline sodium citrate (SSC), $50 \%$ formamide, $1 \mathrm{mg} / \mathrm{ml}$ yeast tRNA, 0.1 $\mathrm{mg} / \mathrm{ml}$ heparin, $0.1 \%$ Tween 20, 0.005-M EDTA, pH 8.0, and $0.1 \%$ CHAPS. Following prehybridization, the tissue was hybridized by incubating in hybridization buffer containing a probe for VGlut2 
(DIG-labeled). Posthybridization stringency washes were performed sequentially at $65^{\circ} \mathrm{C}$ in prewarmed buffers: $1 \times 15 \mathrm{~min}$ in $2 \times \mathrm{SSC}, 3 \times 20$ $\mathrm{min}$ in $0.2 \times$ SSC buffer. Following stringency washes, tissue was further washed at room temperature $2 \times 10 \mathrm{~min}$ in Ts7.5 (0.1 M TRIS- $\mathrm{HCl}, \mathrm{pH}$ $7.5,0.15 \mathrm{M} \mathrm{NaCl}$ ). Tissue was then incubated in $3 \% \mathrm{H}_{2} \mathrm{O}_{2}$ in methanol and washed $3 \times 5$ in TS7.5 to eliminate endogenous hydrogen peroxidase activity. Sections were then incubated for $1 \mathrm{~h}$ in $1 \%$ blocking buffer (PerkinElmer), followed by incubation for $24 \mathrm{~h}$ at $4^{\circ} \mathrm{C}$ in anti-DIG-POD ( $1: 100$ dilution in $1 \%$ blocking buffer). The following day, after washing $3 \times 10 \mathrm{~min}$ in TNT wash buffer $(0.1 \mathrm{~m}$ TRIS- $\mathrm{HCl}, \mathrm{pH} 7.5,0.15 \mathrm{M} \mathrm{NaCl}$, $0.05 \%$ Tween 20 ), sections underwent a tyramide signal amplification with trichostatin A plus DNP 1:50 in amplification diluent. Following a 4 min incubation, sections were vigorously washed with TNT wash buffer $4 \times 10 \mathrm{~min}$ and incubated in a DNP primary antibody conjugated with AlexaFluor 488 (1:500 dilution in TNT; Invitrogen) at $4^{\circ} \mathrm{C}$ overnight. Sections were then washed $3 \times 10$ min with TNT wash buffer and coverslipped with a mounting media containing DAPI as a counterstain (Life Technologies).

\section{Histology, immunohistochemistry, and confocal microscopy}

Mice were anesthetized with pentobarbital, and transcardially perfused with PBS followed by $4 \%$ (w/v) paraformaldehyde in PBS. Brains were then removed and submerged in $4 \%$ paraformaldehyde for $24 \mathrm{~h}$ and transferred to $30 \%$ sucrose in $\mathrm{ddH}_{2} \mathrm{O}$ for $48 \mathrm{~h}$. Forty micrometer brain sections were obtained and subjected to immunohistochemical staining for neuronal cell bodies (NeuroTrace Invitrogen; $640 \mathrm{~nm}$ excitation/660 $\mathrm{nm}$ emission or $435 \mathrm{~nm}$ excitation/455 nm emission). Brain sections were mounted, and $z$-stack and tiled images were captured on a Zeiss LSM 710 confocal microscope using a $20 \times, 40 \times$, or $63 \times$ objective and analyzed using ZEN 2009 and ImageJ software. To determine optical fiber placement, tissue was imaged at $10 \times$ and $20 \times$ on an upright conventional fluorescent microscope.

\section{Open-field behavior}

Four weeks following surgery, VGlut ${ }^{\text {LHA }:: t a C a s p 3}$ and VGlut $2^{\text {LHA }}:$ :Control mice were examined in a custom made open-field arena $(25 \times 25 \times 25 \mathrm{~cm}$ white Plexiglas arena) for $35 \mathrm{~min}$. Center zone was defined as the center $156 \mathrm{~cm}^{2}$ (25\% of the entire arena). Corner zones were defined as the $39 \mathrm{~cm}^{2}$ in each corner. The 35 min session was recorded with a CCD camera that was interfaced with Ethovision software (Noldus Information Technologies). Time spent in the corner and the center of the open-field apparatus was then quantified.

\section{Patch-clamp electrophysiology}

Mice were anesthetized with pentobarbital and perfused transcardially with modified artificial CSF containing the following (in $\mathrm{mM}$ ): $225 \mathrm{su}-$ crose, $119 \mathrm{NaCl}, 1.0 \mathrm{NaH}_{2} \mathrm{PO}_{4}, 4.9 \mathrm{MgCl} 2,0.1 \mathrm{CaCl}_{2}, 26.2 \mathrm{NaHCo}_{3}, 1.25$ glucose. Brains were then rapidly removed and placed in the same solution that was used for perfusion at $\sim 0^{\circ} \mathrm{C}$. Coronal slices containing the LHb $(200 \mu \mathrm{m})$ were cut on a Vibratome (VT-1200, Leica Microsystems). Following slicing, brain slices were placed in a holding chamber and were allowed to recover for at least $30 \mathrm{~min}$ before being placed in the recording chamber and superfused with bicarbonate-buffered solution saturated with $95 \% \mathrm{O}_{2}$ and $5 \% \mathrm{CO}_{2}$ containing the following (in $\mathrm{mm}$ ): $119 \mathrm{NaCl}$, $2.5 \mathrm{KCl}, 1.0 \mathrm{NaH}_{2} \mathrm{PO}_{4}, 1.3 \mathrm{MgCl}_{2}, 2.5 \mathrm{CaCl}_{2}, 26.2 \mathrm{NaHCO}_{3}$, and 11 glucose (at $\left.32^{\circ}-34^{\circ} \mathrm{C}\right)$. Cells were visualized using infrared differential contrast and fluorescence microscopy. For voltage-clamp recordings, patch electrodes (3-5 M $\Omega$ ) were back-filled with a cesium methanesulfonic acid internal solution containing the following (in mM): $117 \mathrm{Cs}$ methanesulfonic acid, 20 HEPES, 0.4 EGTA, 2.8 NaCl, 5 TEA, $2 \mathrm{ATP}$, and 0.2 GTP. For cell-attached recordings, patch electrodes (2-4 M $\Omega$ ) were back-filled with a potassium gluconate internal solution containing the following (in $\mathrm{mm}$ ): $130 \mathrm{~K}$-gluconate, $10 \mathrm{KCl}, 10 \mathrm{HEPES}, 10 \mathrm{EGTA}, 2$ $\mathrm{MgCl}_{2}, 2 \mathrm{ATP}, 0.2 \mathrm{GTP}, \mathrm{pH} 7.35,270-285$ mOsm for all internal solutions. Whole-cell voltage-clamp and cell-attached recordings of LHb neurons were made using an Axopatch 700B amplifier (Molecular Devices). For all optical stimulations, blue light ( $1 \mathrm{~mW}, 473 \mathrm{~nm}$ ) was delivered through a $40 \times$ objective via a LED. Series resistance (15-25 M $\Omega$ ) and/or input resistance were monitored online with a $5 \mathrm{mV}$ hyperpolarizing step delivered between stimulation sweeps. All data were filtered at
$2 \mathrm{kHz}$, digitized at $5-10 \mathrm{kHz}$, and collected using pClamp10 software (Molecular Devices). For voltage-clamp recordings in LHb neurons, membrane potentials were maintained at $-70 \mathrm{mV}$, and then at $+10 \mathrm{mV}$, and light pulses $(5 \mathrm{~ms})$ were delivered every $20 \mathrm{~s}$ to evoke neuronal firing. For EPSCs, following 5-10 min of baseline recording, $10 \mu \mathrm{M}$ of the glutamate antagonist DNQX was bath-applied for $10 \mathrm{~min}$. For IPSCs, following 5-10 min of baseline recording, $10 \mu \mathrm{M}$ of the $\mathrm{GABA}_{\mathrm{A}}$ receptor antagonist, SR-95531 (gabazine) was bath-applied for $10 \mathrm{~min}$. EPSCs and IPSCs were recorded in the presence of $1 \mathrm{~mm} 4-\mathrm{AP}\left(\mathrm{K}^{+}\right.$channel blocker $)$ and $1 \mu \mathrm{M}$ TTX $\left(\mathrm{Na}^{+}\right.$channel blocker) to isolate monosynaptic currents (Cruikshank et al., 2010; Stamatakis et al., 2013). IPSC and EPSC amplitudes were calculated by measuring the peak current from the average response from six sweeps during baseline and during each drug application. Cells that showed a $>20 \%$ change in the holding current or access resistance were excluded from analysis. For cell-attached recordings, a 20 $\mathrm{Hz}$ optical stimulation was delivered for $1 \mathrm{~s}$ every $20 \mathrm{~s}$ for 20 sweeps. Firing rate was averaged across all 20 sweeps. For asynchronous release recordings, a $10 \mathrm{~Hz}$ optical stimulation was delivered for $1 \mathrm{~s}$ every $20 \mathrm{~s}$. Following a 5-10 min baseline recording, $100 \mu \mathrm{M}$ of the membranepermeable calcium buffer, EGTA-AM, was bath-applied for at least 20 min. EPSC frequencies were calculated by averaging the frequency $1 \mathrm{~s}$ before stimulation and $1 \mathrm{~s}$ immediately following stimulation and averaged across four to six sweeps.

\section{Real-time place preference}

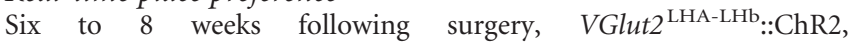
VGlut2 $2^{\text {LHA-LHb }:: N p H R 3.0, ~ a n d ~ V G l u t 2 ~} 2^{\text {LHA-LHb }:: C o n t r o l ~ m i c e ~ b i l a t e r a l l y ~}$ implanted with optical fibers aimed above the LHb were placed in a custom-made behavioral arena $(50 \times 50 \times 25 \mathrm{~cm}$ black Plexiglas) for 20 min. One counterbalanced side of the chamber was assigned as the stimulation side. At the start of the session, the mouse was placed in the nonstimulated side of the chamber. Every time the mouse crossed to the stimulation side of the chamber, a $20 \mathrm{~Hz}$ constant laser stimulation (473 $\mathrm{nm}, 10-12 \mathrm{~mW}$ for VGlut $2^{\mathrm{LHA}-\mathrm{LHb}}::$ ChR2 mice) or a constant $532 \mathrm{~nm}$ laser stimulation $\left(10-12 \mathrm{~mW}\right.$, for VGlut2 ${ }^{\text {LHA-LHAb }:: N p H R 3.0 ~ a n d ~}$ VGlut2 ${ }^{\text {LHA-LHAb }}:$ Control mice) was delivered until the mouse crossed back into the nonstimulation side. Percentage of time spent on the stimulation-paired and velocity was recorded via a CCD camera interfaced with Ethovision software (Noldus Information Technologies).

\section{Photoinhibition of VGlut $2^{L H A-L H b}:: N p H R 3.0$ during reward consumption}

Following the real-time place preference experiments, male VGlut2 ${ }^{\text {LHA-LHb }}:: \mathrm{NpHR} 3.0$ and VGlut2 ${ }^{\text {LHA-LHb }}:$ Control mice were restricted to $90 \%$ of their initial body weight by administering one daily feeding of $\sim 2.5-3.0 \mathrm{~g}$ of standard grain-based chow immediately following each behavioral experiment, if performed. Behavioral training and testing occurred in mouse operant chambers interfaced with optogenetic stimulation equipment as described previously (Stamatakis and Stuber, 2012). Once mice reached $90 \%$ of their body weight, they were trained in a standard behavioral box (Med Associates) equipped with bottle lickometers for quantification of consumption of a highly palatable, calorically dense liquid (Ensure, $0.93 \mathrm{kCal} / \mathrm{ml}$ ). The free-reward consumption task consisted of unlimited access to Ensure during each 20 min session. Lick time stamps were recorded and used for analysis. Mice were trained until the number of licks during each session was stable $(<20 \%$ change) for three consecutive sessions, which for all mice occurred after 7-15 training sessions. Once the mice stabilized they received constant optical inhibition during a 20 min session (10-12 mW $532 \mathrm{~nm}$ light from a solid-state laser delivered via custom-made patch cable). Following reward consumption task, mice received one counterbalanced session each of 0 and $2.5 \mathrm{~mm}$ quinine dissolved in Ensure, with at least $24 \mathrm{~h}$ in between each session.

\section{Data analysis and statistics}

All data are presented as mean \pm SEM. Statistical analysis was assessed using $t$ tests or repeated-measures ANOVA. When ANOVA reached significance, a Bonferroni post hoc comparison was conducted. Nonsignificance was defined as $p>0.05$ and significance as ${ }^{\star} p<0.05$ and ${ }^{\star *} p<0.001$. 
A

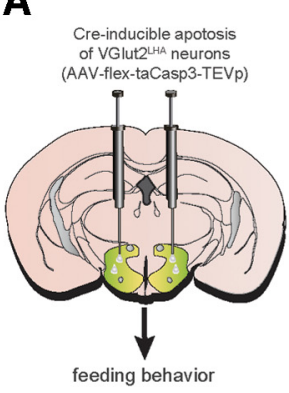

B

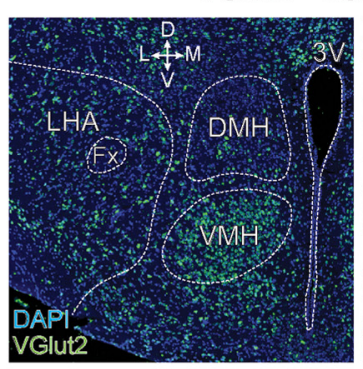

C

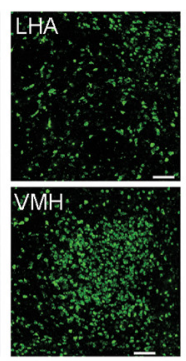

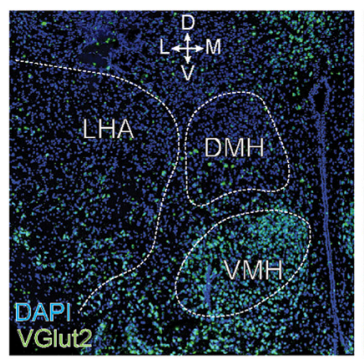

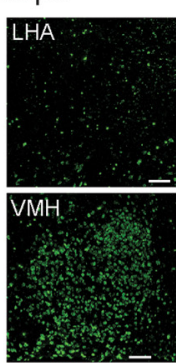

F

D

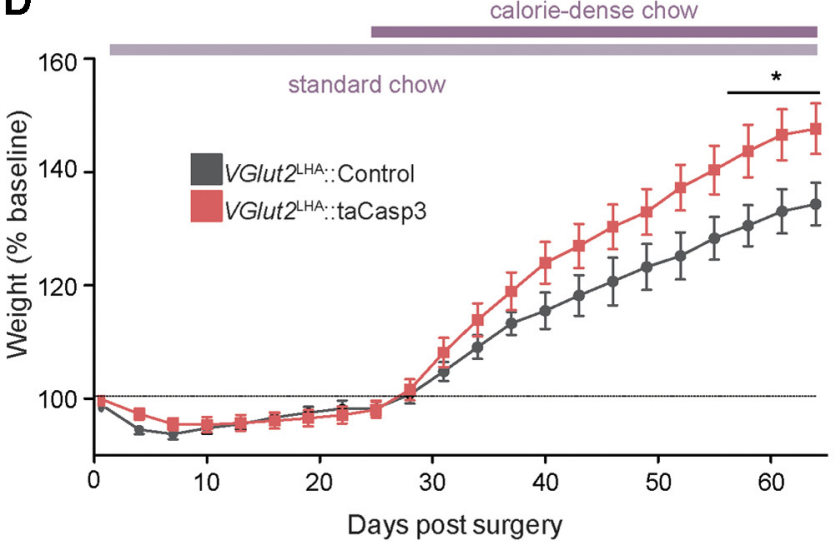

E

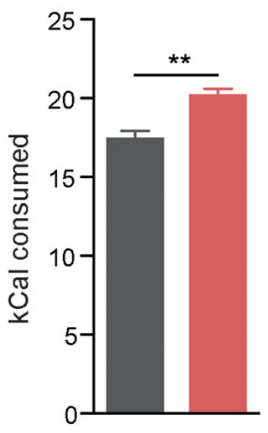

G

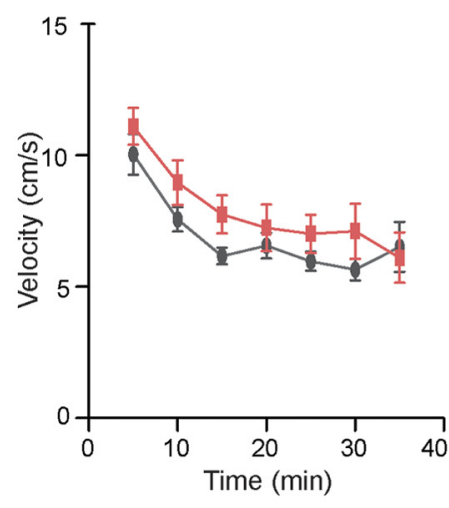

H

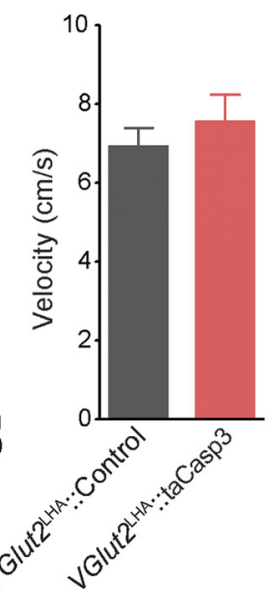

I

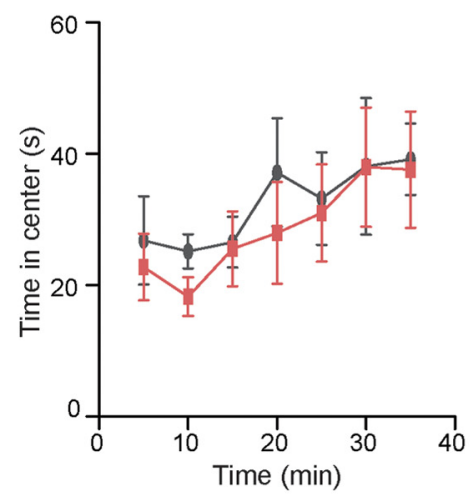

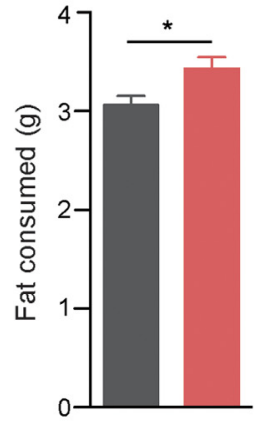

J

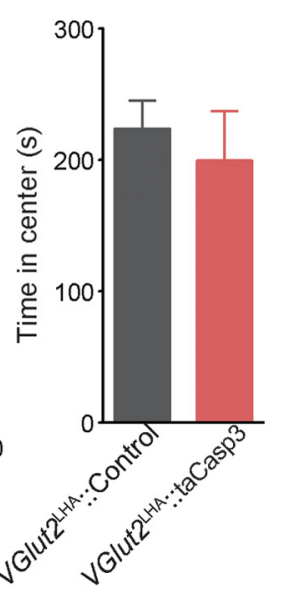

Figure 1. Genetic ablation of LHA glutamatergic neurons increases caloric intake and enhances body weight gain. $A$, Schematic for viral injection of AAV2-FLEX-taCasp3-TEVp into the LHA of

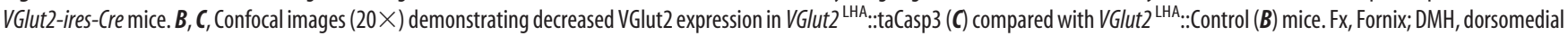
hypothalamic nucleus; VMH, ventromedial hypothalamic nucleus; $3 \mathrm{~V}$, third ventricle; $D$, dorsal; L, lateral; M, medial; V, ventral. Scale bars, $200 \mu \mathrm{m}$. $\boldsymbol{D}$, Ablation of LHA glutamatergic neurons significantly potentiated weight gain induced from a calorie-dense diet. $\boldsymbol{E}$, Ablation of LHA glutamatergic neurons significantly increased caloric intake as measured by the average daily calories consumed over the last $7 \mathrm{~d}$ of exposure to the calorie-dense diet. $\boldsymbol{F}$, Ablation of LHA glutamatergic neurons significantly increased fat intake as measured by the average grams of fat consumed over

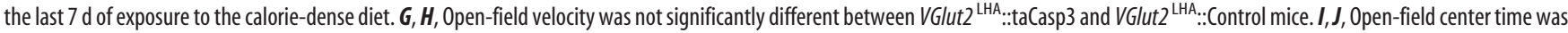

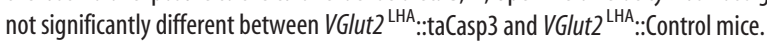

\section{Results}

Our previous work demonstrated that optogenetic stimulation of Vglut2-expressing LHA glutamatergic neurons could acutely suppress feeding (Jennings et al., 2013); however, it is unclear whether these neurons are important in regulating feeding or body weight over days or weeks. Therefore, we selectively ablated glutamatergic neurons in the LHA by injecting a cre-dependent virus (AAV-FLEX-taCasp3-TEVp) encoding a pro-taCaspase-3 and a TEVp enzyme that cleaves pro-taCaspase- 3 into the active, proapoptotic signal caspase-3 (Yang et al., 2013) into VGlut2ires-cre mice (Vong et al., 2011; Fig. 1A-C). Following virus injections, in situ hybridization confirmed that the density of LHA Vglut2 neurons was reduced to $56.8 \pm 15 \%$ compared with controls ( $n=4$ VGlut2-ires-cre caspase-treated mice). We observed no differences in body weight or caloric intake when mice had ad libitum access to standard rodent chow (Fig. 1D). However, when mice were given ad libitum access to a calorie-dense high-fat diet in addition to standard chow, VGlut $2^{\mathrm{LHA}}:$ taCasp 3 mice showed a 

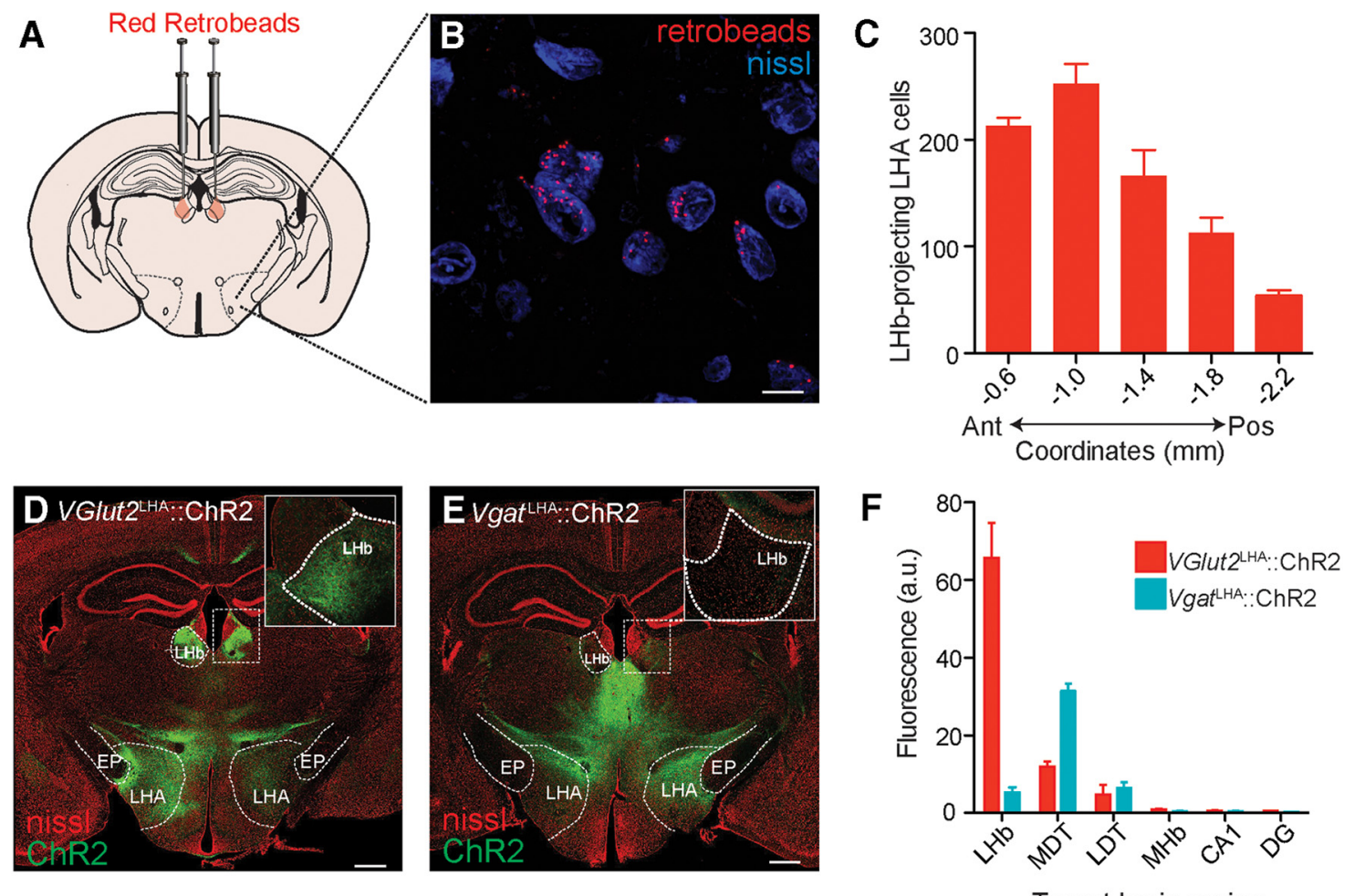

Figure 2. The anterior LHA sends a glutamatergic projection to the LHb. A, Schematic for injection of red retrobeads into the LHb of a C57BL/6J mouse. $B$, Confocal image of the LHA showing LHb-projecting LHA neurons. Scale bar, $20 \mu \mathrm{m}$. C, Quantification of LHb-projecting LHA neurons along the anterior-posterior axis of the LHA. LHb-projecting neurons are significantly denser in the anterior LHA compared with the posterior LHA. Ant, Anterior; Post, posterior. D, Confocal images of coronal sections showing expression of ChR2-eYFP in the LHA and LHb (inset) of a VG/ut2 ${ }^{\text {LHA.: ChR2 }}$

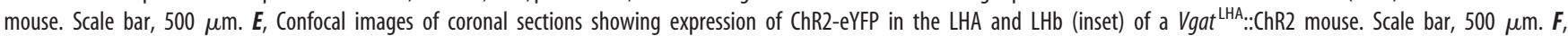

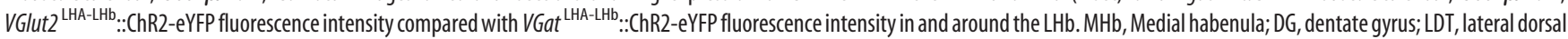
thalamus; MDT, medial dorsal thalamus.

significant increase in body weight (ANOVA for interaction: $F_{(21,308)}=1.77, p=0.02, n=8$ mice per group; Fig. $\left.1 D\right)$, which corresponded to an increase in caloric intake during the last $7 \mathrm{~d}$ of high-fat diet access compared with VGlut2 ${ }^{\mathrm{LHA}}$ :Control mice $\left(t_{(14)}=4.50, p=0.0005, n=8\right.$ mice per group; Fig. $\left.1 E\right)$. Additionally, ablation of LHA glutamatergic neurons preferentially increased the consumption of the high-fat food, without affecting the consumption of the standard chow (standard chow consumed during $7 \mathrm{~d}$ before the introduction of the high-fat diet showed a trend: $t_{(14)}=2.143, p=0.0502$; standard chow consumed during final $7 \mathrm{~d}$ of experiment was not significantly different: $\left.t_{(14)}=1.074, p=0.301\right)$ VGlut2 ${ }^{\mathrm{LHA}}:$ taCasp 3 mice consumed significantly more of the high-fat diet during the last $7 \mathrm{~d}$ of experiment compared with VGlut ${ }^{\mathrm{LHA}}$ :Control mice $\left(t_{(14)}=2.52\right.$, $p=0.02 ; n=8$ mice per group; Fig. $1 F)$.

To determine whether ablation of LHA glutamatergic neurons resulted in changes in locomotor activity or anxiety-like phenotypes, which could indirectly account for changes in food intake, we next tested mice in an open-field assay. Although we observed a slight increase in measured locomotor activity $\left(t_{(14)}=\right.$ $0.75, p=0.46, n=8$ per group; Fig. $1 G, H)$, and a slight decrease in the amount of time spent in the center of the open-field $\left(t_{(14)}=\right.$ $0.28, p=0.77, n=8$ per group; Fig. $1 I, J)$, these results did not reach statistical significance. Collectively, these data demonstrate that genetic ablation of LHA Vglut2 neurons increases caloric intake and body weight gain when mice have ad libitum access to a palatable, high-fat diet.

We next sought to identify LHA glutamatergic projections that may be involved in modulating feeding and reward. The lateral hypothalamus sends widespread projections throughout the brain, including projections to the LHb (Poller et al., 2013). To map the precise location of the LHb-projecting neurons within the LHA, we injected fluorescent retrograde beads into the LHb of wild-type mice (Fig. 2A,B). Three weeks following surgery, we observed neurons in the LHA and entopenduncular nucleus labeled with retrograde transported beads from the LHb. Although LHb-projecting LHA neurons spanned the entire length of the LHA, we observed the highest density of LHbprojecting LHA neurons in the anterior portion of the LHA (ANOVA: $F_{(4,15)}=24.88, p<0.0001, n=4$ sections at different AP locations from $n=3$ mice; Fig. $2 C$ ).

To selectively target LHA neurons, and to trace their axonal projections in and around the LHb, we introduced a creinducible viral construct coding for channelrhodopsin-2 conjugated to enhanced yellow fluorescent protein (ChR2-eYFP) bilaterally into the LHA of VGlut2-ires-cre mice and Vgat-irescre mice to target LHA glutamatergic or GABAergic neurons, respectively (Fig. 2D,E). Six weeks after surgery, we observed robust eYFP expression in the LHA in both mouse lines, but eYFP axonal fiber expression was much higher in the LHb of the VGlut2-ires-cre mice, suggesting that LHA glutamatergic neurons innervate the LHb to a stronger degree compared with LHA GABAergic neurons, consistent with previous studies (Poller et al., 2013).

We next sought to characterize the functional synaptic connectivity between LHA glutamatergic neurons and postsynaptic LHb neurons. Voltage-clamp recordings from postsynaptic LHb neurons in brain slices obtained from VGlut ${ }^{\mathrm{LHA}}:: \mathrm{ChR} 2$ 


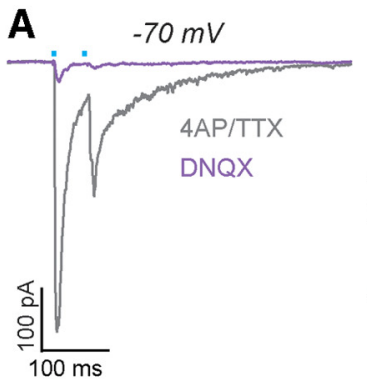

E

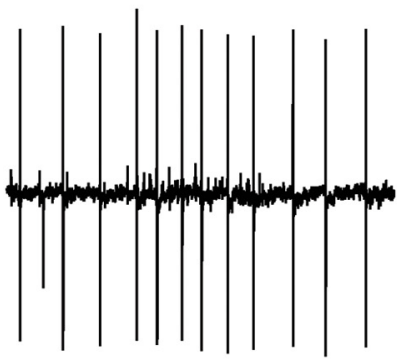

$\overline{50 \mathrm{~ms}}$

H

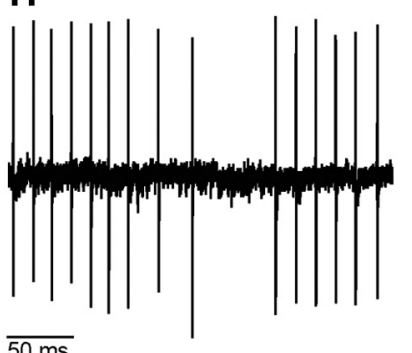

$\overline{50 \mathrm{~ms}}$

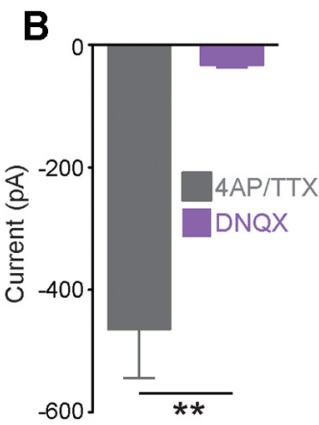

$\mathbf{F}$

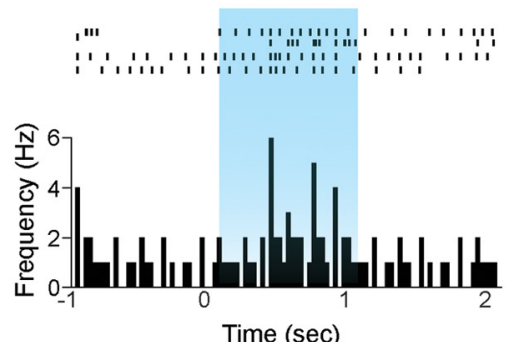

I

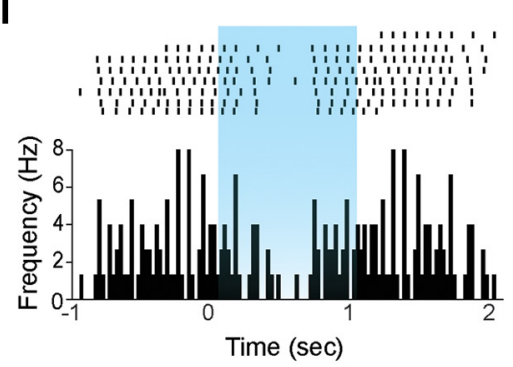

C

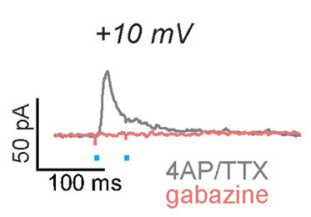

D

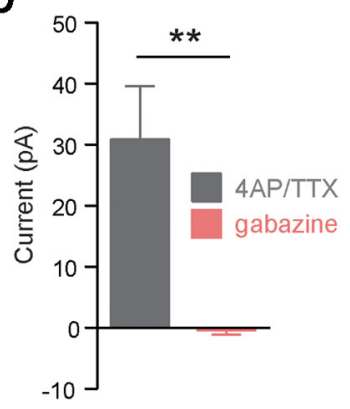

G

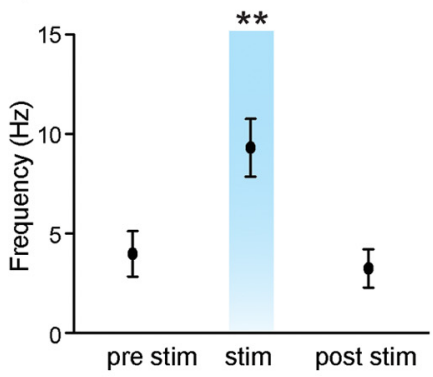

J
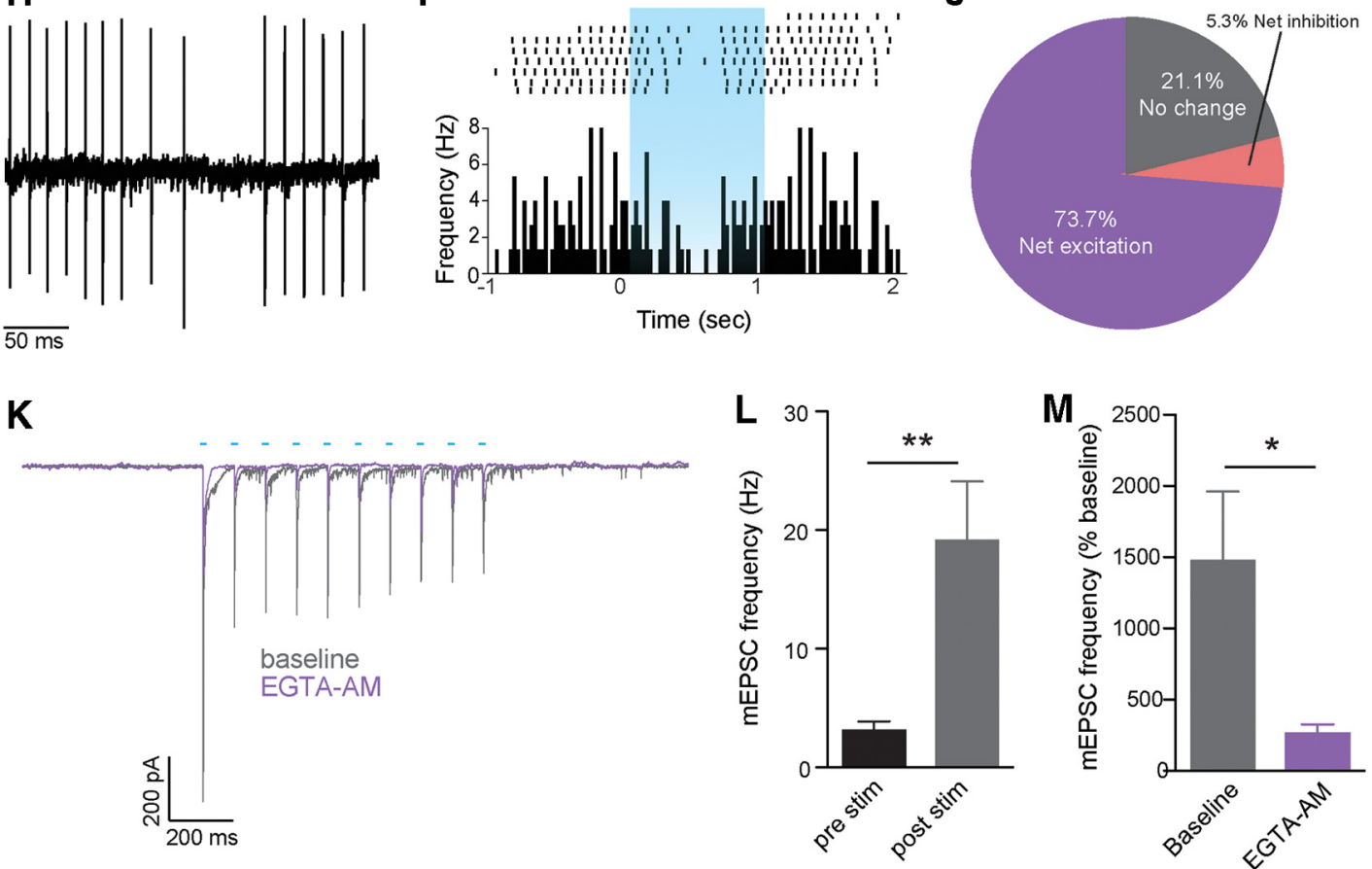

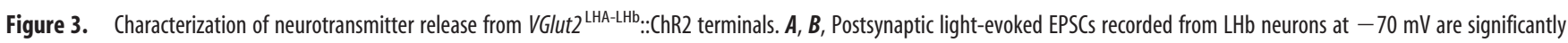
attenuated following bath-application of $10 \mu \mathrm{M}$ DNQX. C, D, Postsynaptic light-evoked IPSCs recorded from LHb neurons at $+10 \mathrm{mV}$ are significantly attenuated by bath-application of $10 \mu \mathrm{M}$ gabazine. $\boldsymbol{E}-\mathbf{G}$, Cell-attached recordings demonstrating a significant increase in the spontaneous firing rate of a subset LHb neurons in response to a $1 \mathrm{~s} 20 \mathrm{~Hz}$ optical stimulation of VGlut2 ${ }^{\mathrm{LHA}-\mathrm{LHB}}:$ :ChR2 terminals in the LHb. $\boldsymbol{H}, \boldsymbol{I}$, Cell-attached recordings demonstrating a decrease in the spontaneous firing rate from a $\mathrm{LHb}$ neurons in response to a $1 \mathrm{~s} 20 \mathrm{~Hz}$ optical stimulation of

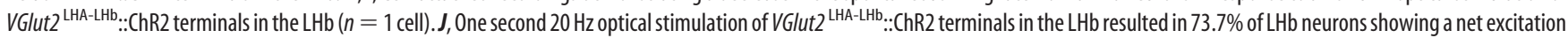
( $n=14$ cells), $21.1 \%$ of $L \mathrm{Hb}$ neurons showing $<20 \%$ change in firing ( $n=4$ cells), and $5.3 \%$ of $L \mathrm{Hb}$ neurons showing a net inhibition ( $n=1$ cell, $n=19$ neurons total). $\boldsymbol{K}$, Asynchronous release

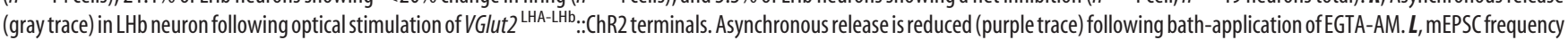
$(\mathrm{Hz})$ is significantly increased during the $1 \mathrm{~s}$ following optical stimulation compared with the $1 \mathrm{~s}$ before optical stimulation. $\boldsymbol{M}, \mathrm{mEPSC}$ frequency (percentage baseline) is significantly reduced following bath-application of EGTA-AM.

mice revealed that light pulses that selectively stimulated VGlut ${ }^{\mathrm{LHA}}:$ :ChR2 fibers within the LHb, produced light-evoked currents that were blocked by the glutamate receptor antagonist $\operatorname{DNQX}\left(t_{(22)}=5.4, p<0.0001, n=13\right.$ cells; Fig. $\left.3 A, B\right)$. At the reversal potential for AMPA receptors, we observed a smallamplitude light-evoked current that was blocked by the $\mathrm{GABA}_{\mathrm{A}}$ receptor antagonist, gabazine $\left(t_{(14)}=3.6, p=0.003\right.$, $n=8$ cells; Fig. $3 C, D)$. Although we observed an excitatory 
current in nearly all LHb neurons we recorded from (42/46 neurons, $91 \%$ ), we observed a smaller percentage of neurons that displayed an inhibitory current (8/12 neurons, 66.6\%). Cell-attached recordings from LHb neurons revealed that when we delivered a 1 s $20 \mathrm{~Hz}$ optical pulse-train to selectively stimulate VGlut2 ${ }^{\mathrm{LHA}}:$ :ChR2 terminals, the majority of LHb neurons displayed increases in their spontaneous firing rates (14/19 neurons, $73.7 \% ; F_{(2,39)}=8.53, p=0.0008, n=14$ cells; Fig. $3 E-G, J)$. We also observed a minority of LHb neurons that displayed a decrease in spontaneous firing following optical stimulation ( $n=1 / 19$ neurons, 5.3\%; Fig. $3 H-J$ ). These data suggest that the net effect of neurotransmitter release following stimulation of VGlut $2^{\mathrm{LHA}}:: \mathrm{ChR} 2$ terminals is to increase the firing rate of postsynaptic LHb neurons.

Following a brief $10 \mathrm{~Hz}$ optical pulse train, we also observed delayed asynchronous EPSCs in a subset of LHb neurons we recorded from ( $18 / 28$ neurons, $64.3 \% ; t_{(32)}=3.15, p=0.004$, $n=17$ cells; Fig. $3 \mathrm{~K}, L)$, a phenomenon which has previously been demonstrated in other hypothalamic circuits (Atasoy et al., 2012). This asynchronous glutamatergic release was observed in both the presence and absence of $4-\mathrm{AP}\left(\mathrm{K}^{+}\right.$channel blocker) and TTX ( $\mathrm{Na}^{+}$channel blocker; Cruikshank et al., 2010), indicating that this asynchronous release was likely not due to local LHb polysynaptic network activity. The presence of delayed EPSCs was significantly attenuated by bath application of EGTA-AM, a membrane-permeable calcium buffer, suggesting that the asynchronous release is due to a build up of calcium in presynaptic LHA terminals $\left(t_{(12)}=2.47, p=0.03\right.$, $n=7$ cells; Fig. $3 K, M$ ).

Given that optogenetic activation of LHA glutamatergic neurons produces aversion-related phenotypes (Jennings et al., 2013), and that the LHA sends a dense projection to the LHb, we next examined the functional role of the LHA-LHb projection in modulating feeding and reward-related phenotypes using in vivo optogenetics. To selectively modulate the activity of the LHALHb circuit, we injected VGlut2-ires-cre mice with either creinducible ChR2-eYFP (VGlut2 ${ }^{\text {LHA-LHb }:: C h R 2), ~ c r e-i n d u c i b l e ~}$ eYFP (VGlut2 ${ }^{\text {LHA-LHb}}:$ :Control), or cre-inducible halorhodop$\sin 3.0$ (VGlut2 ${ }^{\mathrm{LHA}-\mathrm{LHb}}:: \mathrm{NpHR} 3.0$ ), and bilaterally implanted optical fibers above the LHb (Figs. 2D, 4A,B). Optogenetic stimulation of VGlut $2^{\text {LHA-LHb }}$ terminals decreased time spent in a location paired with optical stimulation $\left(t_{(10)}=5.9, p<0.001, n=5\right.$

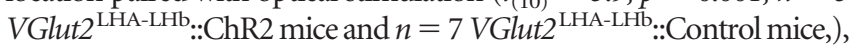
whereas optogenetic inhibition of VGlut $2^{\mathrm{LHA}-\mathrm{LHb}}$ terminals increased time spent in a location paired with optical inhibition $\left(t_{(12)}=2.579, p=\right.$ $0.017, n=7$ mice per group; Fig. 4C-E). Optogenetic inhibition of this circuit also resulted in a significant increase in the consumption of a highly palatable calorically dense liquid in VGlut2 ${ }^{\text {LHA-LHb}:: N p H R 3.0 ~}$ mice, compared with VGlut $2^{\mathrm{LHA}-\mathrm{LH} b}::$ Control mice (total licks: $t_{(12)}=$ $2.374, p=0.035$; licking bouts: $t_{(12)}=2.63, p=0.02$; inter-bout interval: $t_{(12)}=2.56, p=0.02, n=7$ mice per group; Fig. $\left.4 F-H\right)$. When the solution was adulterated with quinine to reduce the palatable qualities without alternating the caloric content, both VGlut $2^{\text {LHA-LHb: }: \mathrm{NpHR} 3.0}$ mice and VGlut $2^{\mathrm{LHA}-\mathrm{LHb}}::$ Control mice showed a comparable number of licks (ANOVA for interaction of quinine concentration vs inhibition group: $F_{(1,24)}=4.57, p=0.04$, Fig. $4 I$ ) suggesting that the LHA-LHb glutamatergic circuit is important in modulating consumption of palatable caloric substances.

\section{Discussion}

Although distinct populations of molecularly defined neurons or precise synaptic connections can regulate aspects of behavior, multiple functionally distinct elements likely coopera- tively orchestrate complex behavioral states, such as feeding. Some circuit components, such as AgRP/NPY producing neurons in the arcuate nucleus, are uniquely positioned to directly sense and respond to the changing metabolic state of the organism to promote feeding (van den Top et al., 2004; Luquet et al., 2005; Aponte et al., 2011; Krashes et al., 2011; Atasoy et al., 2012; Chen et al., 2015), whereas various cell groups in the LHA may facilitate or suppress appetitive and consummatory behaviors directed toward feeding (Jennings et al., 2013, 2015). Previous studies have suggested that the LHA may generate motivated behavioral states directed toward feeding by directly regulating the activity of VTA dopaminergic neurons (Harris et al., 2005; Leinninger et al., 2009; Nieh et al., 2015). Indeed, previous anatomical tracing studies have demonstrated that the LHA sends a dense projection to the VTA (Geisler and Zahm, 2005; Geisler et al., 2007), and that direct modulation of LHA fibers in the VTA can facilitate both feeding and reward-related phenotypes (Kempadoo et al., 2013; Nieh et al., 2015), although it appears this is likely mediated mostly by inhibitory projections from the LHA that preferentially target VTA GABAergic neurons, which in turn should disinhibit VTA dopaminergic neurons.

Electrolytic or chemical lesions of the LHA produce weight loss and aphagia (Harrell et al., 1975; Schallert and Whishaw, 1978; Von Der Porten and Davis, 1979). However, here we demonstrate that genetic ablation of LHA glutamatergic neurons produces an increases in caloric intake and body weight after weeks of ad libitum access to a high-fat diet, suggesting that LHA glutamatergic neurons may be involved in long-term regulation of food intake and body weight. It is important to note that this experiment was performed to determine the net effect of loss of LHA glutamatergic neurons, regardless of their projection target. Future experiments are needed to determine whether pathway-specific ablation of LHA glutamatergic subpopulations (such as those that project to the LHb or VTA) produce similar phenotypes to those observed with nonprojection-specific ablation. Additionally, the LHA contains GABAergic neurons, as well as glutamatergic neurons, and in situ hybridization data suggest that the population of GABAergic LHA neurons may be substantially larger than the population of glutamatergic neurons (Rosin et al., 2003; Meister, 2007). Importantly, genetic ablation of LHA GABAergic neurons dramatically suppresses feeding, and reduces motivation for palatable caloric rewards (Jennings et al., 2015), which is consistent with the classically described phenotypes induced by electrolytic or chemical LHA lesions. These data underscore the heterogeneity of the LHA and further demonstrate that different genetically distinct cell groups, as well as circuit connectivity, can differentially regulate feeding behaviors.

Because we observed an effect on feeding and body weight following genetic ablation of LHA glutamatergic neurons (regardless of projection target), we decided to investigate an output of the LHA, which may be mediating these effects. We found that the LHA sends a strong projection to the LHb, an area involved in promoting aversion and negatively regulating reward-related behaviors. Previous data has demonstrated a similar aversive phenotype when activating LHb inputs from the entopenduncular nucleus, an output of the basal ganglia that is located lateral to the LHA (Shabel et al., 2012). It is important to note that the entopenduncular nucleus and lateral hypothalamic area are neighboring structures and it is possible that viral targeting of one region could result in viral transduction of the neighboring region. Following retrobead 
A

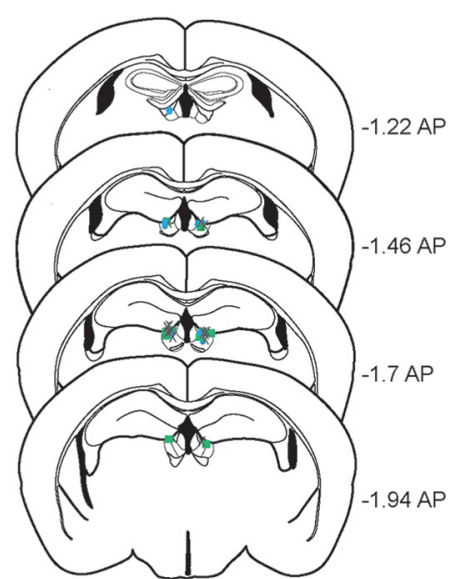

Fiber Placements

- VGlut2 $2^{\text {LHA-LHb ::ChR2 }}$

$X$ VGlut2 $2^{\text {LHA-LHb }: \text { Contro }}$

- VGlut2 ${ }^{\text {LHA-LHb::NpHR3.0 }}$
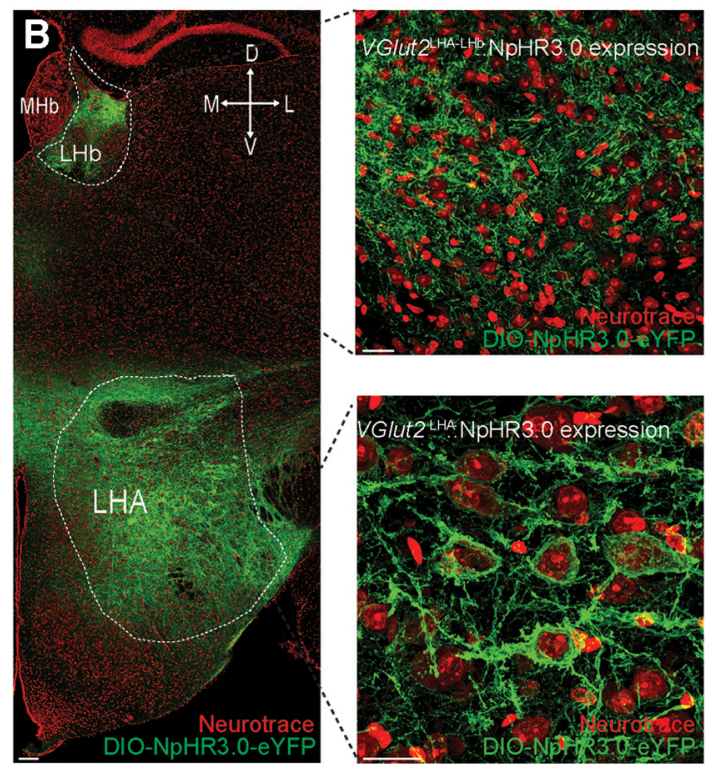

C

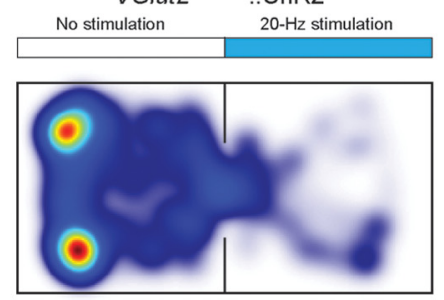

$\mathbf{F}$

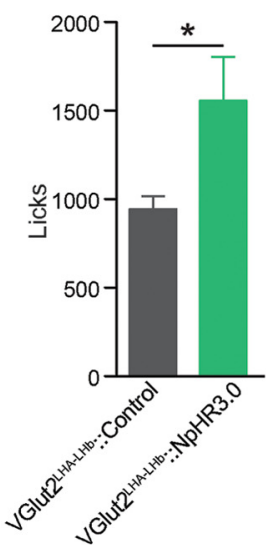

G

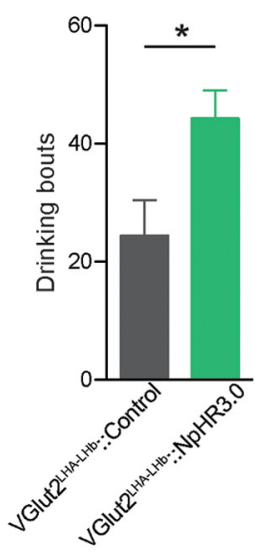

D

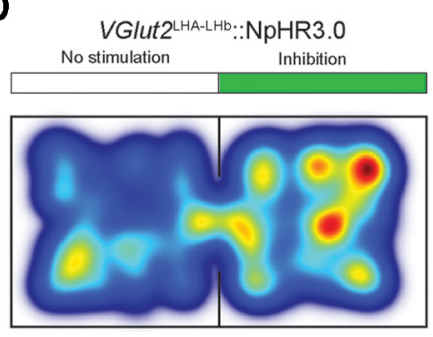

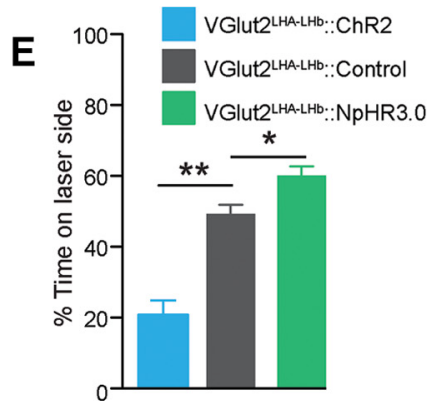

H

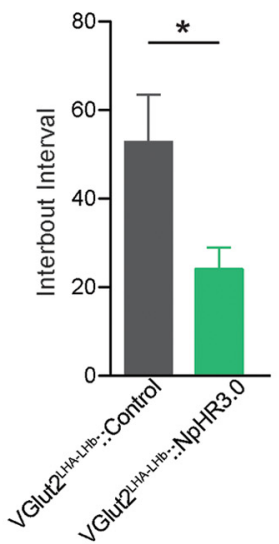

I

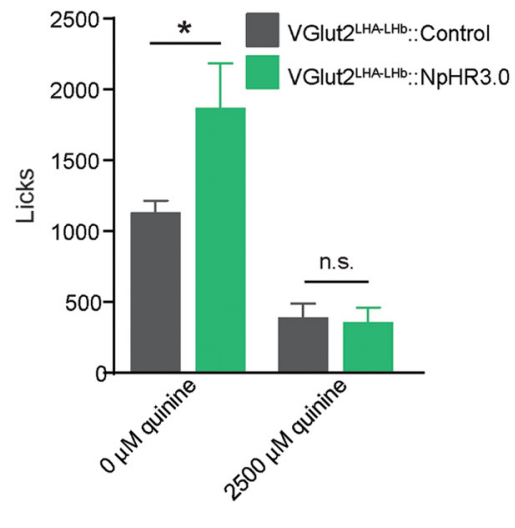

Figure 4. Optogenetic modulation of the VGlut2 ${ }^{\mathrm{LHA}-\mathrm{LHb}}$ circuit acutely modulates feeding and reward-related behaviors. $\boldsymbol{A}$, Schematic diagram showing optical fiber placements for

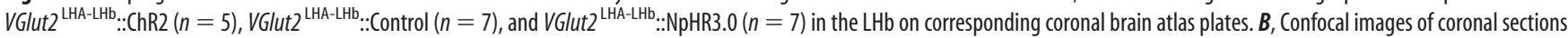
showing expression of NpHR3.0-eYFP in the LHA (Scale bars: left, $100 \mu \mathrm{m}$; bottom right, $20 \mu \mathrm{m}$ ) and LHb (Scale bar, $20 \mu \mathrm{m}$ ) of a VGlut2-ires-cre mouse. C, $\boldsymbol{D}$, Representative heat maps showing

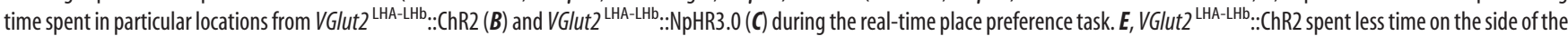

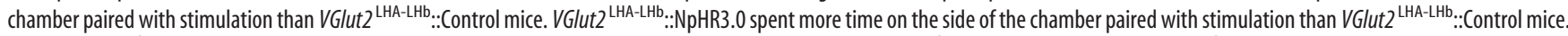

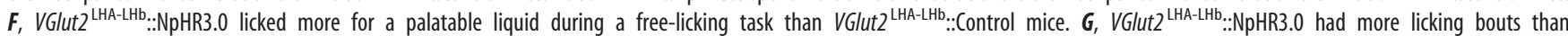

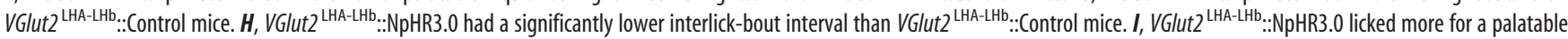

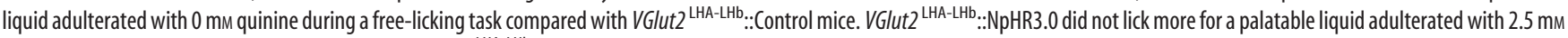

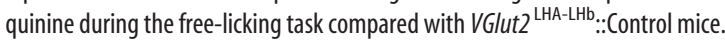

injections into the $\mathrm{LHb}$, we observed LHb-projecting neurons in both the entopenduncular nucleus and the LHA. However, the entopenduncular nucleus, and the globus pallidus internus (the primate homolog) contains mainly GABAergic neurons (Oertel et al., 1984; Stephenson et al., 2005). However, it was recently shown that some entopenduncular projections to the LHb can switch from using GABA to glutamate under certain conditions (Shabel et al., 2014). In addition, our method for targeting the LHA glutamatergic neurons, using cre-inducible ChR2 and medial injection sites, did not result 
in substantial infection of entopenduncular neurons (Fig. $2 D$ ), supporting our conclusions that our behavioral phenotypes are the result of the modulation of LHA glutamatergic projections, rather than entopenduncular projections to the LHb.

We observed both excitatory and inhibitory responses in LHb neurons following optical stimulation of VGlut $2^{\text {LHA-LHb }}$ fibers (Fig. 2 ). This could be due to co-release of GABA and glutamate from the same LHA neuron or terminal, or due to ectopic cre expression in nonglutamatergic LHA neurons. Previous studies have demonstrated the specificity for cre-inducible viruses to target glutamate neurons in other brain regions in the VGlut2-Cre mouse, such as the bed nucleus of the stria terminalis (Jennings et al., 2013). However, it is unclear whether this is the case in the LHA, and thus further studies should be conducted to determine whether LHb-projecting LHA neurons are capable of co-releasing both glutamate and GABA, and if so, under what conditions. Interestingly, recent studies have demonstrated that other LHb inputs, from the VTA and entopenduncular nucleus as mentioned above, also co-release GABA and glutamate (Root et al., 2014; Shabel et al., 2014), suggesting that this may be a phenomena that is generalizable to many LHb inputs. It still remains unclear what the function of GABA and glutamate corelease is within this system. It has been speculated that the co-release of GABA and glutamate may help to tightly regulate the firing of $\mathrm{LHb}$ neurons, to filter the firing of specific inputs, or to provide presynaptic loci of plasticity. Another possibility worth considering is that LHA-LHb neuronal phenotypes are not static, but instead dynamically regulated by factors, such as development, physiological changes, stress, or other environmental factors.

The data presented here demonstrate that in addition to the direct LHA-VTA circuits that modulate feeding and reward (Nieh et al., 2015), the glutamatergic projections from the LHA to the LHb also can bidirectionally control reward and feeding, by increasing LHb neuronal activity, to suppress ongoing behavior, or decreasing glutamatergic tone in the LHb to promote ongoing behavior. Collectively, these findings suggest that the LHA is well positioned to both directly regulate VTA neurons and indirectly regulate them via their projections to the LHb. Although these data, as well as data from previous studies, suggest that glutamate projection neurons in the LHA function to negatively regulate feeding and reward, these conclusions are primarily drawn from experiments where these cells are directly modulated with optogenetics. It remains unclear whether LHA glutamate neurons actually encode select aspects of feeding or reward or, whether under normal conditions, they are participant in other aspects of behavior, such as arousal. Future studies are thus needed determine whether neurons of the LHA that project to either the VTA or LHb differentially encode aspects of appetitive and consummatory behavior related to feeding.

\section{References}

Aponte Y, Atasoy D, Sternson SM (2011) AGRP neurons are sufficient to orchestrate feeding behavior rapidly and without training. Nat Neurosci 14:351-355. CrossRef Medline

Atasoy D, Betley JN, Su HH, Sternson SM (2012) Deconstruction of a neural circuit for hunger. Nature 488:172-177. CrossRef Medline

Berk ML, Finkelstein JA (1982) Efferent connections of the lateral hypothalamic area of the rat: an autoradiographic investigation. Brain Res Bull 8:511-526. CrossRef Medline

Berthoud HR, Münzberg H (2011) The lateral hypothalamus as integrator of metabolic and environmental needs: from electrical self-stimulation to opto-genetics. Physiol Behav 104:29-39. CrossRef Medline

Chen Y, Lin YC, Kuo TW, Knight ZA (2015) Sensory detection of food rapidly modulates arcuate feeding circuits. Cell 160:829-841. CrossRef Medline

Christoph GR, Leonzio RJ, Wilcox KS (1986) Stimulation of the lateral habenula inhibits dopamine-containing neurons in the substantia nigra and ventral tegmental area of the rat. J Neurosci 6:613-619. Medline

Cruikshank SJ, Urabe H, Nurmikko AV, Connors BW (2010) Pathwayspecific feedforward circuits between thalamus and neocortex revealed by selective optical stimulation of axons. Neuron 65:230-245. CrossRef Medline

Geisler S, Zahm DS (2005) Afferents of the ventral tegmental area in the rat-anatomical substratum for integrative functions. J Comp Neurol 490: 270-294. CrossRef Medline

Geisler S, Derst C, Veh RW, Zahm DS (2007) Glutamatergic afferents of the ventral tegmental area in the rat. J Neurosci 27:5730-5743. CrossRef Medline

Harrell LE, Decastro JM, Balagura S (1975) A critical evaluation of body weight loss following lateral hypothalamic lesions. Physiol Behav 15:133136. CrossRef Medline

Harris GC, Wimmer M, Aston-Jones G (2005) A role for lateral hypothalamic orexin neurons in reward seeking. Nature 437:556-559. CrossRef Medline

Hoebel BG, Teitelbaum P (1962) Hypothalamic control of feeding and selfstimulation. Science 135:375-377. CrossRef Medline

Jennings JH, Rizzi G, Stamatakis AM, Ung RL, Stuber GD (2013) The inhibitory circuit architecture of the lateral hypothalamus orchestrates feeding. Science 341:1517-1521. CrossRef Medline

Jennings JH, Ung RL, Resendez SL, Stamatakis AM, Taylor JG, Huang J, Veleta K, Kantak PA, Aita M, Shilling-Scrivo K, Ramakrishnan C, Deisseroth K, Otte S, Stuber GD (2015) Visualizing hypothalamic network dynamics for appetitive and consummatory behaviors. Cell 160:516-527. CrossRef Medline

Kempadoo KA, Tourino C, Cho SL, Magnani F, Leinninger GM, Stuber GD, Zhang F, Myers MG, Deisseroth K, de Lecea L, Bonci A (2013) Hypothalamic neurotensin projections promote reward by enhancing glutamate transmission in the VTA. J Neurosci 33:7618-7626. CrossRef Medline

Krashes MJ, Koda S, Ye C, Rogan SC, Adams AC, Cusher DS, Maratos-Flier E, Roth BL, Lowell BB (2011) Rapid, reversible activation of AgRP neurons drives feeding behavior in mice. J Clin Invest 121:1424-1428. CrossRef Medline

Lammel S, Lim BK, Ran C, Huang KW, Betley MJ, Tye KM, Deisseroth K, Malenka RC (2012) Input-specific control of reward and aversion in the ventral tegmental area. Nature 491:212-217. CrossRef Medline

Leinninger GM, Jo YH, Leshan RL, Louis GW, Yang H, Barrera JG, Wilson H, Opland DM, Faouzi MA, Gong Y, Jones JC, Rhodes CJ, Chua S Jr, Diano S, Horvath TL, Seeley RJ, Becker JB, Münzberg H, Myers MG Jr (2009) Leptin acts via leptin receptor-expressing lateral hypothalamic neurons to modulate the mesolimbic dopamine system and suppress feeding. Cell Metab 10:89-98. CrossRef Medline

Luquet S, Perez FA, Hnasko TS, Palmiter RD (2005) NPY/AgRP neurons are essential for feeding in adult mice but can be ablated in neonates. Science 310:683-685. CrossRef Medline

Margules DL, Olds J (1962) Identical "feeding" and "rewarding" systems in the lateral hypothalamus of rats. Science 135:374-375. CrossRef Medline

Matsui A, Williams JT (2011) Opioid-sensitive GABA inputs from rostromedial tegmental nucleus synapse onto midbrain dopamine neurons. J Neurosci 31:17729-17735. CrossRef Medline

Matsumoto M, Hikosaka O (2007) Lateral habenula as a source of negative reward signals in dopamine neurons. Nature 447:1111-1115. CrossRef Medline

Meister B (2007) Neurotransmitters in key neurons of the hypothalamus that regulate feeding behavior and body weight. Physiol Behav 92:263271. CrossRef Medline

Nieh EH, Matthews GA, Allsop SA, Presbrey KN, Leppla CA, Wichmann R, Neve R, Wildes CP, Tye KM (2015) Decoding neural circuits that control compulsive sucrose seeking. Cell 160:528-541. CrossRef Medline

Oertel WH, Nitsch C, Mugnaini E (1984) Immunocytochemical demonstration of the GABA-ergic neurons in rat globus pallidus and nucleus entopeduncularis and their GABA-ergic innervation. Adv Neurol 40:9198. Medline

Poller WC, Madai VI, Bernard R, Laube G, Veh RW (2013) A glutamatergic pro- 
jection from the lateral hypothalamus targets VTA-projecting neurons in the lateral habenula of the rat. Brain Res 1507:45-60. CrossRef Medline

Root DH, Mejias-Aponte CA, Qi J, Morales M (2014) Role of glutamatergic projections from ventral tegmental area to lateral habenula in aversive conditioning. J Neurosci 34:13906-13910. CrossRef Medline

Rosin DL, Weston MC, Sevigny CP, Stornetta RL, Guyenet PG (2003) Hypothalamic orexin (hypocretin) neurons express vesicular glutamate transporters VGLUT1 or VGLUT2. J Comp Neurol 465:593-603. CrossRef Medline

Saper CB, Chou TC, Elmquist JK (2002) The need to feed: homeostatic and hedonic control of eating. Neuron 36:199-211. CrossRef Medline

Schallert T, Whishaw IQ (1978) Two types of aphagia and two types of sensorimotor impairment after lateral hypothalamic lesions: observations in normal weight, dieted, and fattened rats. J Comp Physiol Psychol 92: 720-741. Medline

Shabel SJ, Proulx CD, Trias A, Murphy RT, Malinow R (2012) Input to the lateral habenula from the basal ganglia is excitatory, aversive, and suppressed by serotonin. Neuron 74:475-481. CrossRef Medline

Shabel SJ, Proulx CD, Piriz J, Malinow R (2014) Mood regulation. GABA/glutamate co-release controls habenula output and is modified by antidepressant treatment. Science 345:1494-1498. CrossRef Medline

Stamatakis AM, Stuber GD (2012) Activation of lateral habenula inputs to the ventral midbrain promotes behavioral avoidance. Nat Neurosci 15: 1105-1107. CrossRef Medline

Stamatakis AM, Jennings JH, Ung RL, Blair GA, Weinberg RJ, Neve RL, Boyce F, Mattis J, Ramakrishnan C, Deisseroth K, Stuber GD (2013) A unique population of ventral tegmental area neurons inhibits the lateral habenula to promote reward. Neuron 80:1039-1053. CrossRef Medline

Stephenson DT, Li Q, Simmons C, Connell MA, Meglasson MD, Merchant K, Emborg ME (2005) Expression of GAD65 and GAD67 immunoreactivity in MPTP-treated monkeys with or without L-DOPA administration. Neurobiol Dis 20:347-359. CrossRef Medline

van den Top M, Lee K, Whyment AD, Blanks AM, Spanswick D (2004) Orexigen-sensitive NPY/AgRP pacemaker neurons in the hypothalamic arcuate nucleus. Nat Neurosci 7:493-494. CrossRef Medline

Von Der Porten K, Davis JR (1979) Weight loss following LH lesions independent of changes in motor activity or metabolic rate. Physiol Behav 23:813-819. Medline

Vong L, Ye C, Yang Z, Choi B, Chua S Jr, Lowell BB (2011) Leptin action on GABAergic neurons prevents obesity and reduces inhibitory tone to POMC neurons. Neuron 71:142-154. CrossRef Medline

Yang CF, Chiang MC, Gray DC, Prabhakaran M, Alvarado M, Juntti SA, Unger EK, Wells JA, Shah NM (2013) Sexually dimorphic neurons in the ventromedial hypothalamus govern mating in both sexes and aggression in males. Cell 153:896-909. CrossRef Medline 